\title{
ANALISIS PERANCANGAN APLIKASI PUSAT INFORMASI (E-PusIn) BERBASIS WEB : STUDI KASUS KAMPUS UNISKA BANJARMASIN
}

\author{
Galih Mahalisa, M. Kom \\ Fakultas Teknologi Informasi, Universitas Islam Kalimantan Muhammad Arsyad Al Banjari Banjarmasin \\ Email : galih.mahalisa@gmail.com
}

\begin{abstract}
ABSTRAK
Sistem informasi merupakan sistem yang mencakup sejumlah komponen (manusia, komputer, teknologi informasi, dan prosedur kerja), ada sesuatu yang diproses (data menjadi informasi), dan dimaksudkan untuk mencapai suatu sasaran atau tujuan. Permasalahan yang terjadi adalah ketidaktahuan pengunjung dalam mencari lokasi ruangan atau denah kampus karena belum tersedianya fasilitas / stand sebagai pusat informasi kampus yang terletak di tengah lobby gedung utama. Berdasarkan hasil analisa dengan melakukan observasi pada pada hari dan jam kerja sekitar $80 \%$ pengujung yang pertama kali datang ke uniska, akan bertanya kepada orang sekitar yang ada di lobby, $15 \%$ tamu menunggu di lobby yang kemudian dijemput oleh yang berkepentingan, dan sisanya mencari tahu sendiri dengan cara berkeliling kampus. Metode yang digunakan berdasarkan studi kasus, untuk pengujian perangkat lunak menggunakan standard ISO 9126. Hasil pengujian dan analisa yang ddidapatkan dari 15 orang responden, maka hasil pengujian functionality menyatakan $88 \%$ termasuk skor baik untuk pengelolaan fungsi-fungsi pada aplikasi, hasil uji usability menyatakan 68\% cukup baik untuk pengguna dalam menggunakan sistem, dan dalam hal maintainability pada pengujian aplikasi ini sangat bagus dalam hal pengembangan aplikasi yang lebih baik
\end{abstract}

Kata Kunci : sistem, informasi, kampus, lobby, aplikasi, pengujung, tamu

\section{PENDAHULUAN}

Sistem berasal dari bahasa Latin (systèma) dan bahasa Yunani (sustèma) adalah suatu kesatuan yang terdiri komponen atau elemen yang dihubungkan bersama untuk memudahkan aliran informasi, materi atau energi untuk mencapai suatu tujuan. Istilah ini sering dipergunakan untuk menggambarkan suatu set entitas yang berinteraksi, di mana suatu model matematika seringkali bisa dibuat. (https://id.wikipedia.org/wiki/Sistem diakses tgl 19 September 2018).

Universitas Islam Kalimantan (UNISKA)

Muhammad Arsyad Al Banjary adalah PTS tertua dan terbesar di Kalimantan Selatan, didirikan oleh yayasan UNISKA berdasarkan akte Notaris Bachtiar Nomor 6 tanggal 7 Juli 1981. Saat ini telah memiliki Program PACASARJANA, 9 Sembilan) Fakultas, 17 (Tujuh Belas) Program Studi S-1. Ke-9 Fakultas dan Program Pascasarjana. Kampus utama di Banjarmasin memiliki 5 buah gedung yaitu Gedung A (lobby), Gedung B (sebelah Kanan), Gedung C (berhadapan gedung A), Gedung D (sebelah kiri), dan Gedung E (sebelah kiri) dengan berbagai nama ruangan, dan banyaknya dosen dan karyawan yang ada di Gedung UNISKA

Permasalahan yang terjadi adalah ketidaktahuan pengunjung dalam mencari lokasi ruangan atau denah kampus. Untuk sistem yang digunakan sekarang masih media kertas untuk menggambarkan denah ruangan atau gedung. Jika denah tersebut tidak terlihat, mereka bisa bertanya kepada orang lain untuk mendapatkan informasi gedung atau ruangan yang jelas. Berdasarkan permasalahn tersebut sistem yang akan dibuat akan memudahkan mahasiswa baru maupun para pengujung tanpa harus malu bertanya kepada orang lain. Maka dari itu perlunya suatu sistem yang mengelola pencarian yang kemudian ditampilkan pada layar monitor yang nantikan akan ditempatkan 
di lobby, pencarian hanya seputar posisi gedung, letak ruangan, letak fakultas, sampai pencarian nama-nama dosen untuk menampilan homebase dari dosen tersebut. Informasi tadi kemudian akan ditampilkan melalui monitor agar lebih informatif.

\section{METODE PENELITIAN}

Desain penelitian yang dipakai adalah Studi Kasus yang merupakan penelitian yang memusatkan perhatian pada suatu kasus tertentu dengan menggunakan individu atau kelompok sebagai bahan studinya. Dalam hal ini kasus ini difokuskan untuk menganalisa pola pengujung dan mengumpulkan hasil observasi yang lebih dalam terhadap pengunjung.

Berdasarkan hasil observasi dari studi kasus yang didapatkan, maka penelitian ini menggunakan pendekatan penelitian dan pengembangan ( Research and Development) adalah metode yang digunakan untuk menghasilkan produk tertentu dan menguji daripada keefektifan produk tersebut bagi pengguna.

Pendekatan model perangkat lunak untuk mendukung penelitian ini menggunakan model waterfall, yang melalui beberapa tahapan, yaitu:

1. Tahap analisis kebutuhan

2. Tahap desain

3. Tahap implementasi

4. Tahap pengujian

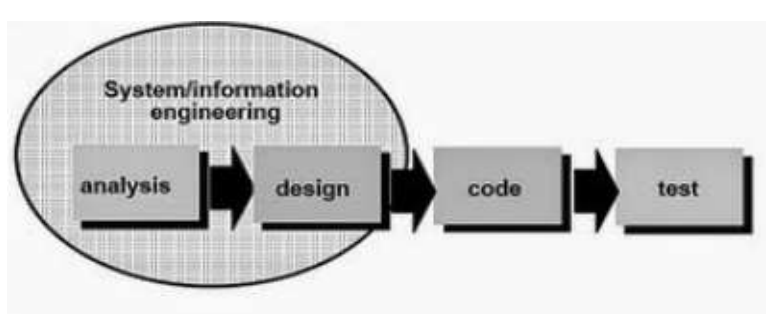

Gambar 1 Model Waterfall

Proses pengumpulan observasi data dilakukan dengan 2 cara yaitu :

1. Pengumpulan data primer, dengan melakukan survey sesuai dengan kebutuhan data

2. Pengumpulan data sekunder, dikumpulkan dengan mengamati data dan mempelajari data tersebut.
Langkah-langkah yang ditempuh dalam menyelesaikan penelitian sebagai berikut:

1. Studi literatur

Pada tahap ini penulis mencari literatur dengan rincian sebagai berikut:

a. Mencari referensi mengenai sistem yang terkait.

b. Mencari permasalahan yang biasa ditemui

2. Analisis sistem

Pada tahap ini dilakukan analisis masalah dari objek penelitian dan kebutuhan sistem yang akan dibuat, termasuk batasan-batasan masalah pada sistem.

3. Perancangan dan implementasi sistem

Pada tahap ini dilakukan perancangan sesuai dengan hasil dari analisis sistem dan dilanjutkan dengan meng-implementasi hasil analisis dan perancangan ke dalam sistem

4. Pengujian

Pada tahap ini dilakukan pengujian sistem apakah berjalan sesuai dengan tujuan penelitian demgam menggunakan standard ISO 9126

5. Penyusunan laporan

Pada tahap ini dilakukan penulisan dokumentasi hasil analisis dan implementasi dari sistem dalam bentuk laporan penelitian.

\section{HASIL DAN PEMBAHASAN}

a. Analisis Kebutuhan

Instrumen yang diperlukan sebagai pendukung untuk menganalisa kebutuhan sistem ini adalah menggunakan media kuisioner dengan 10 orang pengunjung sebagai responden sebelum adanya aplikasi E-PusIn.

Hasil dari responden yaitu sebagai berikut :

Tabel 1 Pola Respon Pengujung

\begin{tabular}{lc}
\hline \multicolumn{1}{c}{ Variabel } & Presentase \\
\hline $\begin{array}{l}\text { Bertanya sekitar lobby } \\
\text { /satpam }\end{array}$ & $70 \%$ \\
\hline $\begin{array}{l}\text { Telah berkoordinasi } \\
\text { dan menunggu di lobby }\end{array}$ & $20 \%$ \\
\hline Mencari tahu sendiri & $10 \%$ \\
\hline
\end{tabular}


b. Tahap Desain

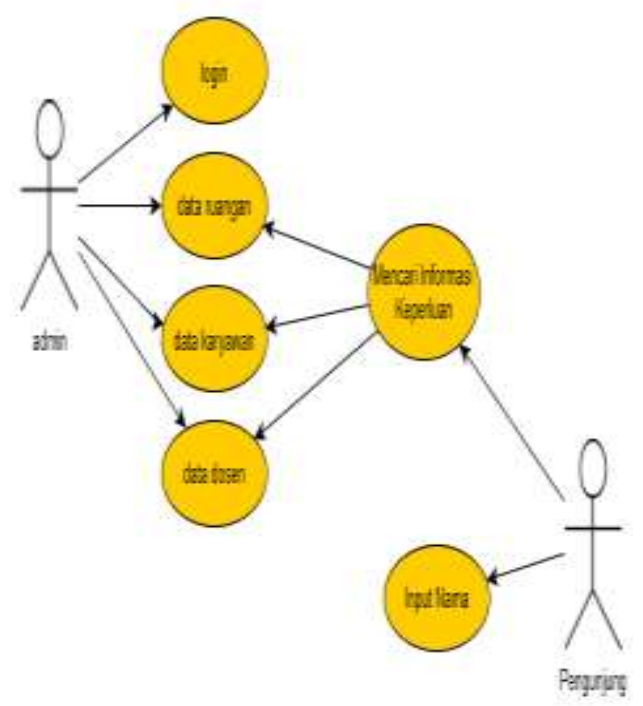

Gambar 2 Usecase

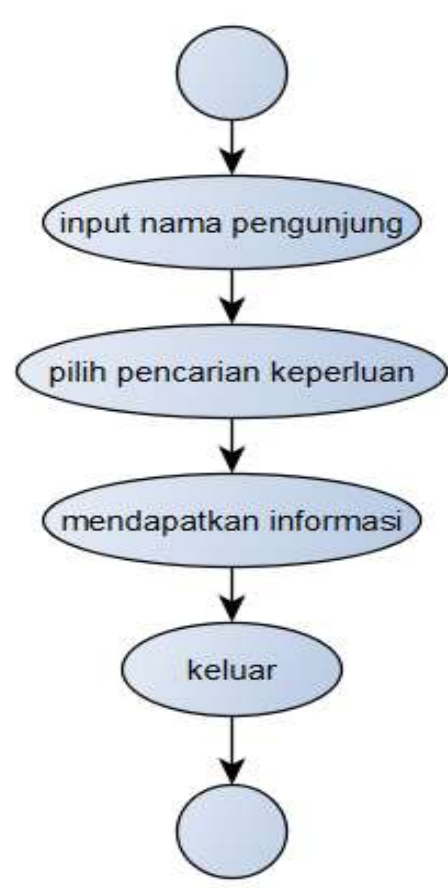

Gambar 4 Activity Pengunjung

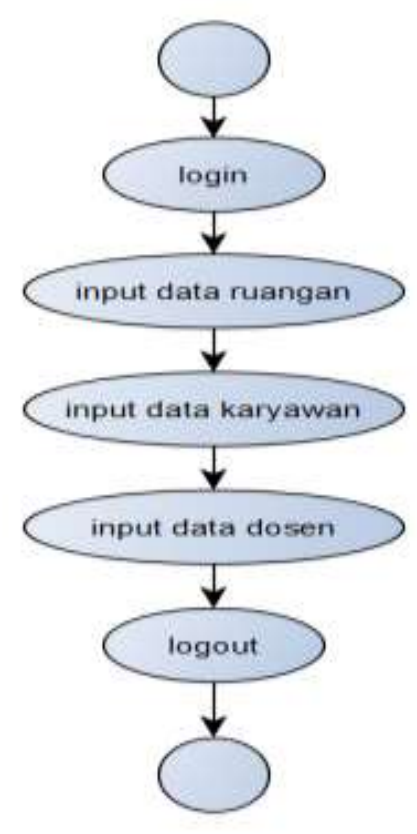

Gambar 3 Activity Admin c. Tahap Implementasi

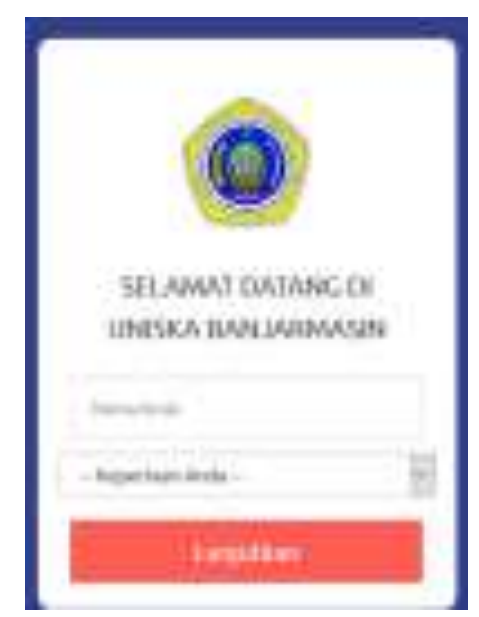

Gambar 5 Login Pengunjung 


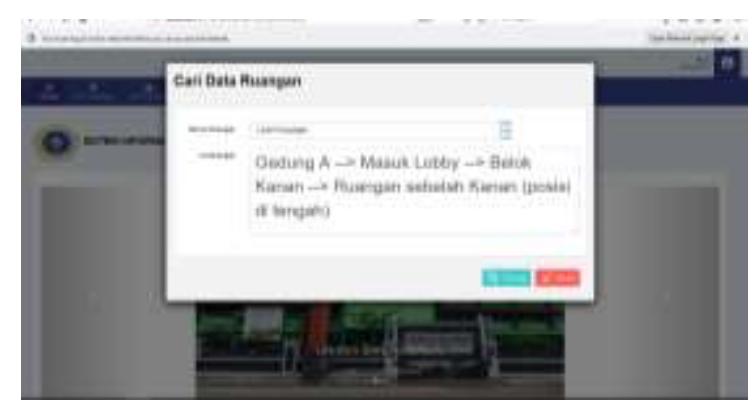

Gambar 6 Pencarian Ruangan

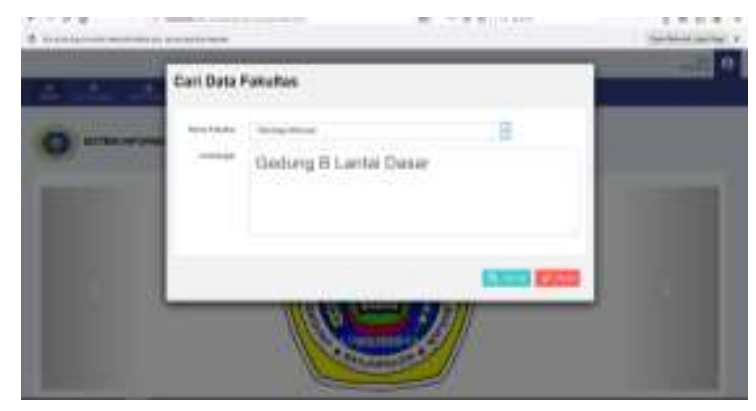

Gambar 7 Pencarian Fakultas

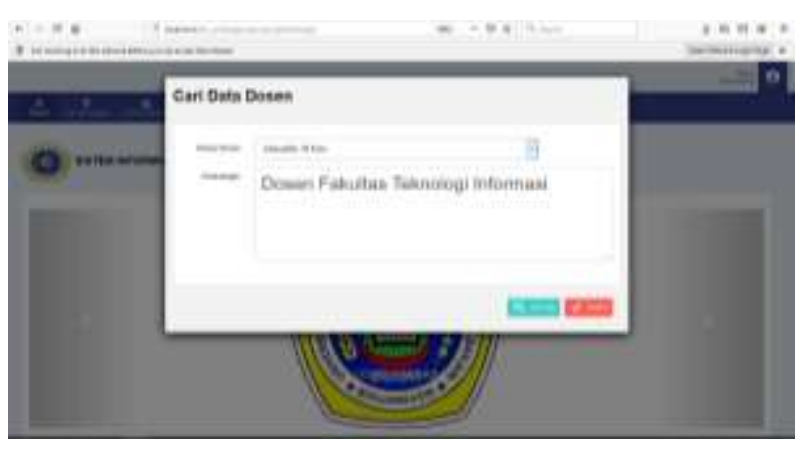

Gambar 8 Pencarian Dosen

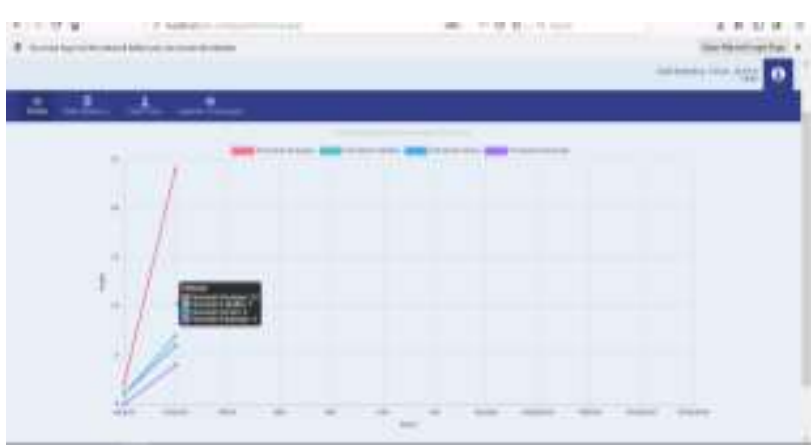

Gambar 9 Statistik Pengunjung

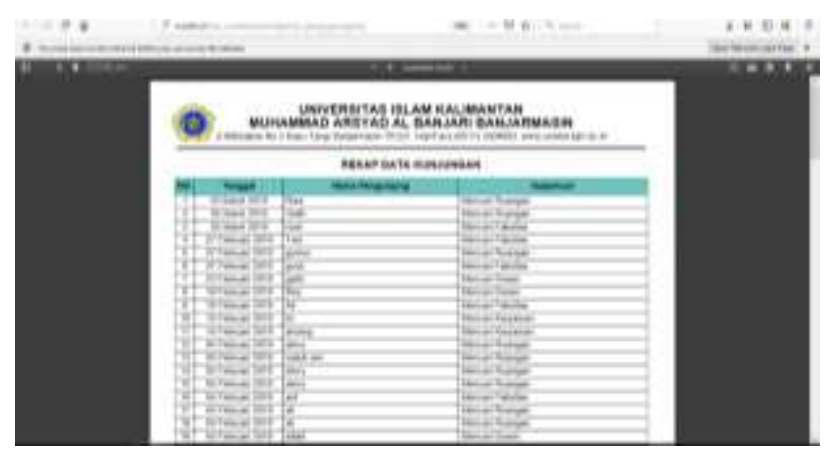

Gambar 10 Rekapitulasi Pengujung

\section{d. Tahap Pengujian}

Pada tahap pengujian ini sistem informasi yang akan diuji kemudian diberikan berbagai rangkaian pengujian kualitas perangkat lunak yang menggunakan beberapa instrumen penelitian sesuai standart ISO 9126, sehingga dapat dilakukan evaluasi sistem tersebut terutama pada aspek functionality, security, usability, efficiency, maintainability, dan portability

Hasil Pengujian Functionality

Responden 15 Orang

Pengujian Functionality

Tabel 2 Pengujian Functionality

\begin{tabular}{|c|c|c|c|}
\hline No & Pertanyaan & $\mathbf{Y a}$ & Tidak \\
\hline 1 & $\begin{array}{l}\text { Apakah fungsi } \\
\text { untuk mengakses } \\
\text { login admin sudah } \\
\text { berfungsi dengan } \\
\text { benar? }\end{array}$ & 15 & 0 \\
\hline 2 & $\begin{array}{l}\text { Apakah fungsi } \\
\text { untuk mengakses } \\
\text { halaman } \\
\text { pengunjung sudah } \\
\text { berfungsi dengan } \\
\text { benar? }\end{array}$ & 15 & 0 \\
\hline 3 & $\begin{array}{l}\text { Apakah halaman } \\
\text { menu utama pada } \\
\text { admin berfungsi } \\
\text { dengan benar? }\end{array}$ & 15 & 0 \\
\hline
\end{tabular}




\begin{tabular}{|c|c|c|c|}
\hline 4 & $\begin{array}{l}\text { Apakah halaman } \\
\text { menu utama pada } \\
\text { pengunjung } \\
\text { berfungsi dengan } \\
\text { benar? }\end{array}$ & 15 & 0 \\
\hline 5 & $\begin{array}{l}\text { Apakah menu } \\
\text { pencarian data } \\
\text { fakultas pada } \\
\text { halaman pengujung } \\
\text { berfungsi dengan } \\
\text { benar? }\end{array}$ & 15 & 0 \\
\hline 6 & $\begin{array}{l}\text { Apakah menu } \\
\text { pencarian data } \\
\text { dosen pada } \\
\text { halaman pengujung } \\
\text { berfungsi dengan } \\
\text { benar? }\end{array}$ & 15 & 0 \\
\hline 7 & $\begin{array}{l}\text { Apakah menu } \\
\text { pencarian data } \\
\text { ruangan pada } \\
\text { halaman pengujung } \\
\text { berfungsi dengan } \\
\text { benar? }\end{array}$ & 15 & 0 \\
\hline 8 & $\begin{array}{l}\text { Apakah menu } \\
\text { pencarian data } \\
\text { karyawan pada } \\
\text { halaman pengujung } \\
\text { berfungsi dengan } \\
\text { benar? }\end{array}$ & 15 & 0 \\
\hline 9 & $\begin{array}{l}\text { Apakah menu input } \\
\text { data fakultas pada } \\
\text { halaman admin } \\
\text { berfungsi dengan } \\
\text { benar? }\end{array}$ & 15 & 0 \\
\hline 10 & $\begin{array}{l}\text { Apakah menu input } \\
\text { data dosen pada } \\
\text { halaman admin } \\
\text { berfungsi dengan } \\
\text { benar? }\end{array}$ & 15 & 0 \\
\hline 11 & $\begin{array}{l}\text { Apakah menu input } \\
\text { data ruangan pada } \\
\text { halaman admin } \\
\text { berfungsi dengan } \\
\text { benar? }\end{array}$ & 15 & 0 \\
\hline 12 & $\begin{array}{l}\text { Apakah menu input } \\
\text { data karyawan pada } \\
\text { halaman admin } \\
\text { berfungsi dengan } \\
\text { benar? }\end{array}$ & 15 & 0 \\
\hline 13 & $\begin{array}{l}\text { Apakah menu cetak } \\
\text { data pada halaman } \\
\text { admin berfungsi }\end{array}$ & 15 & 0 \\
\hline
\end{tabular}

dengan benar?

\begin{tabular}{|c|c|c|c|}
\hline 14 & $\begin{array}{l}\text { Apakah hasil } \\
\text { pencarian ruangan } \\
\text { pada halaman } \\
\text { pengunjung } \\
\text { menampilkan } \\
\text { informasi dengan } \\
\text { benar? }\end{array}$ & 11 & 4 \\
\hline 15 & $\begin{array}{l}\text { Apakah hasil } \\
\text { pencarian dosen } \\
\text { pada halaman } \\
\text { pengunjung } \\
\text { menampilkan } \\
\text { informasi dengan } \\
\text { benar? }\end{array}$ & 14 & 1 \\
\hline 16 & $\begin{array}{l}\text { Apakah hasil } \\
\text { pencarian Fakultas } \\
\text { pada halaman } \\
\text { pengunjung } \\
\text { menampilkan } \\
\text { informasi dengan } \\
\text { benar? }\end{array}$ & 12 & 3 \\
\hline 17 & $\begin{array}{l}\text { Apakah hasil } \\
\text { pencarian karyawan } \\
\text { pada halaman } \\
\text { pengunjung } \\
\text { menampilkan } \\
\text { informasi dengan } \\
\text { benar? }\end{array}$ & 11 & 4 \\
\hline 18 & $\begin{array}{l}\text { Apakah } \\
\text { penginputan data } \\
\text { fakultas pada } \\
\text { halaman admin } \\
\text { berfungsi dengan } \\
\text { benar? }\end{array}$ & 15 & 0 \\
\hline 19 & $\begin{array}{l}\text { Apakah } \\
\text { penginputan data } \\
\text { dosen pada } \\
\text { halaman admin } \\
\text { berfungsi dengan } \\
\text { benar? }\end{array}$ & 15 & 0 \\
\hline 20 & $\begin{array}{l}\text { Apakah } \\
\text { penginputan data } \\
\text { ruangan pada } \\
\text { halaman admin } \\
\text { berfungsi dengan } \\
\text { benar? }\end{array}$ & 15 & 0 \\
\hline 21 & $\begin{array}{l}\text { Apakah } \\
\text { penginputan data } \\
\text { karyawan pada } \\
\text { halaman admin } \\
\end{array}$ & 15 & 0 \\
\hline
\end{tabular}




\begin{tabular}{|c|c|c|c|}
\hline & $\begin{array}{l}\text { berfungsi dengan } \\
\text { benar? }\end{array}$ & & \\
\hline 22 & $\begin{array}{l}\text { Apakah cetak data } \\
\text { pengunjung pada } \\
\text { halaman admin } \\
\text { berfungsi dengan } \\
\text { benar? }\end{array}$ & 11 & 4 \\
\hline 23 & $\begin{array}{l}\text { Apakah informasi } \\
\text { Statistik pengujung } \\
\text { berfungsi dengan } \\
\text { benar? }\end{array}$ & 11 & 4 \\
\hline 24 & $\begin{array}{l}\text { Apakah halaman } \\
\text { kontak berfungsi } \\
\text { informasi dengan } \\
\text { benar? }\end{array}$ & 6 & 9 \\
\hline \multirow[t]{2}{*}{25} & $\begin{array}{l}\text { Apakah halaman } \\
\text { link berfungsi } \\
\text { informasi dengan } \\
\text { benar? }\end{array}$ & 0 & 15 \\
\hline & Total & 331 & 44 \\
\hline
\end{tabular}

Dari hasil diatas dapat diketahui persentase untuk masing-masing penilaian, yaitu

$$
\begin{array}{llll}
\text { YA } & 0,8826667 & \times 100 \% & 88 \% \\
\text { TIDAK } & 0,1173333 & \text { x } 100 \% & 12 \%
\end{array}
$$

Analisis Data Pengujian Functionality

$$
0,882666667 \times 100 \% \quad 88 \%
$$

Berdasarkan analisis deskriptif dan perhitungan maka diperoleh persentase $88 \%$ dari pengujian Functionality. Dari skor persentase yang didapat maka kualitas perangkat lunak dari sisi Functionality telah sesuai dengan atribut Functionality dan mempunyai skala yang cukup baik.

\section{Pengujian Security}

\begin{tabular}{|c|c|c|c|}
\hline & $\begin{array}{l}\text { password-guessing } \\
\text { attack }\end{array}$ & & \\
\hline 3 & $\begin{array}{l}\text { Possible sensitive } \\
\text { directories }\end{array}$ & Low & 1 \\
\hline 4 & $\begin{array}{l}\text { User credentials } \\
\text { are sent in clear } \\
\text { text }\end{array}$ & Low & 2 \\
\hline 5 & Broken links & $\begin{array}{l}\text { informat } \\
\text { ional }\end{array}$ & 3 \\
\hline 6 & $\begin{array}{l}\text { Email address } \\
\text { found }\end{array}$ & $\begin{array}{l}\text { informat } \\
\text { ional }\end{array}$ & 0 \\
\hline 7 & $\begin{array}{l}\text { Password type } \\
\text { input with } \\
\text { autocomplete } \\
\text { enabled }\end{array}$ & $\begin{array}{l}\text { informat } \\
\text { ional }\end{array}$ & 3 \\
\hline
\end{tabular}

Tabel 3 Pengujian Security

\begin{tabular}{llll}
\hline No & $\begin{array}{l}\text { Jenis Celah } \\
\text { Keamanan }\end{array}$ & $\begin{array}{l}\text { Tingkat } \\
\text { Peringat } \\
\text { an }\end{array}$ & $\begin{array}{l}\text { Juml } \\
\text { ah }\end{array}$ \\
\hline 1 & File upload & Low & 1 \\
\hline 2 & Login page & Low & 2 \\
\hline
\end{tabular}

Analisis data pengujian security

Tabel 4 Analisa Data Pengujian Security

\begin{tabular}{lll}
\hline No & Tingkat peringatan & Jumlah \\
\hline 1 & High & - \\
\hline 2 & Medium & - \\
\hline 3 & Low & 6 \\
\hline 4 & informational & 6 \\
\hline & Total & 12 \\
\hline
\end{tabular}

Berdasarkan hasil analisis security yang diuji pada kualitas aplikasi, maka untuk sisi celah keamanan pada sistem ini bisa dikatakan telah sesuai dengan kualitas perangkat lunak yang baik.

\section{Analisis Pengujian Usability}

Tabel 5 Analisis Pengujian Usability

\begin{tabular}{ccc}
\hline $\begin{array}{c}\text { Perta } \\
\text { nyaa } \\
\mathrm{n}\end{array}$ & $\begin{array}{c}\text { Skor } \\
\text { Total }\end{array}$ & $\begin{array}{c}\text { Skor } \\
\text { Maksimum }\end{array}$ \\
\hline 1 & 32 & 60 \\
\hline 2 & 53 & 60 \\
\hline 3 & 32 & 60 \\
\hline 4 & 31 & 60 \\
\hline 5 & 33 & 60 \\
\hline 6 & 42 & 60 \\
\hline 7 & 58 & 60 \\
\hline 8 & 19 & 60 \\
\hline 9 & 47 & 60 \\
\hline 10 & 45 & 60 \\
\hline 11 & 51 & 60 \\
\hline
\end{tabular}




\begin{tabular}{ccc}
\hline 12 & 57 & 60 \\
\hline 13 & 46 & 60 \\
\hline 14 & 31 & 60 \\
\hline 15 & 26 & 60 \\
\hline 16 & 24 & 60 \\
\hline 17 & 46 & 60 \\
\hline 18 & 44 & 60 \\
\hline 19 & 45 & 60 \\
\hline 20 & 49 & 60 \\
\hline 21 & 43 & 60 \\
\hline 22 & 48 & 60 \\
\hline 23 & 45 & 60 \\
\hline 24 & 48 & 60 \\
\hline 25 & 50 & 60 \\
\hline 26 & 38 & 60 \\
\hline 27 & 32 & 60 \\
\hline Total & 1115 & 1620 \\
\hline & &
\end{tabular}

$$
0,688272 \times 100 \% \quad 68 \%
$$

Berdasarkan hasil analisa pengujian usability maka diperoleh presentase 68\%. Dari skor tersebut untuk aplikasi yang sederhana termasuk dalam kategori cukup baik.

Pengujian efficiency

Tabel 6 Pengujian Efficiency

\begin{tabular}{lll}
\hline No & Parameter Dasar Yslow & Aktif \\
\hline 1 & Make fewer HTTP requests & Ya \\
\hline 2 & $\begin{array}{l}\text { Compress components with } \\
\text { GZIP }\end{array}$ & Ya \\
\hline 3 & Reduce DNS lookups & Ya \\
\hline 4 & $\begin{array}{l}\text { Reduce the number of } \\
\text { DOM elements }\end{array}$ & Ya \\
\hline 5 & $\begin{array}{l}\text { Configure entity tags } \\
\text { (Etags) }\end{array}$ & Ya \\
\hline 6 & Use cookie-free domains & \\
\hline 7 & $\begin{array}{l}\text { Make JavaScript and CSS } \\
\text { external }\end{array}$ & \\
\hline
\end{tabular}

Hasil analisa Pengujian maintainability

Tabel 7 Hasil Pengujian Maintainability Aspek Hasil yang diperoleh

Instrumentatio $\mathrm{n}$ Ketika ada kesalahan yang dilakukan oleh user

\begin{tabular}{ll}
\hline & pada saat login, maka \\
& sistem akan mengeluarkan \\
& peringatan untuk \\
& mengidentifikasi \\
& kesalahan \\
\hline Consistency & Pada bentuk rancangan \\
& sistem mempunyai bentuk \\
& yang sama, dapat dilihat \\
& dari segi implementasi \\
& dimana tampilan halaman \\
& web dari satu halaman ke \\
& halaman lainnya memiliki \\
& kemiripan, bentuk yang \\
& serupa dan konsisten \\
\hline Himplicity & Hasil pengujian \\
& menunjukan bahwa sistem \\
& mudah untuk \\
& dikembangkan \\
\hline
\end{tabular}

Hasil analisa pengujian portability

Tabel 8 Hasil Analisa pengujian portability

\begin{tabular}{lll}
\hline No & \multicolumn{1}{c}{ Browser } & \multicolumn{1}{c}{ Hasil } \\
\hline 1 & Mozila firefox & Tidak ditemukan error \\
\hline 2 & $\begin{array}{l}\text { Internet } \\
\text { explorer }\end{array}$ & Tidak ditemukan error \\
\hline 3 & Google Chrome & Tidak ditemukan error \\
\hline 4 & Opera & Tidak ditemukan error \\
\hline
\end{tabular}

\section{KESIMPULAN}

Berdasarkan hasil penelitian dan pengujian yang dilakukan dengan beberapa responden, maka dapat disimpulkan yaitu:

1. Dari tahap functionality untuk pengujian perangkat lunak dari segi fungsi -fungsi dari aplikasi memperoleh presentase $88 \%$ yang termasuk dalam kategori baik

2. Dari segi usability hasil analisa pengujian maka diperoleh presentase $68 \%$. Dari skor tersebut untuk aplikasi yang sederhana termasuk dalam kategori cukup baik.

Saran dari penelitian yang telah dilakukan adalah sebagai berikut :

1. Tampilan masih sederhana jadi bisa dikembangkan agar tidak monoton 
2. Sistem hasil pencarian bisa dikembangkan lagi dengan menambahkan gambar 3D agar lebih menarik

3. Karena berbasis web, untuk sistem keamanan harus ditingkatkan

\section{REFERENSI}

1] A. Kadir, "Pengenalan Sistem Informasi," Am. Enterp. Inst. Public Policy Res., 2014.

2] FN. Jovan, "Panduan Praktis Membuat WEB dengan PHP utk Pemula," MediaKita., 2014.

3] Mahalisa, G. (2018).

PERANCANGAN SISTEM

INFORMASI KAMPUS (SIK)

BERBASIS WEBSITE STUDI

KASUS KAMPUS UNISKA.

SEMINASTIKA UNIVERSITAS

MULIA BALIKPAPAN, 1(001), 101-

103.

4] Mahalisa, G., \& Syafarina, G. A. (2018). ANALISIS PERANCANGAN E-SCHEDULE PERKULIAHAN. Technologia: Jurnal Ilmiah, 9(3), 185187.

5] Y. Utama, "Sistem Informasi Berbasis Web Jurusan Sistem Informasi Fakultas Ilmu Komputer Universitas
Sriwijaya,” J. Sist. Inf., 2011.

6] A. Prayitno and Y. Safitri, "Pemanfaatan Sistem Informasi Perpustakaan Digital Berbasis Website Untuk Para Penulis," Softw. Eng., 2015.

7] D. Puspitasari, "Sistem Informasi Perpustakaan Sekolah Berbasis Web," J. Pilar Nusa Mandiri, 2016.

8] A. P. M. A. Arif, Nur Saiful; Wanda, "Aplikasi Administrasi Perpustakaan Berbasis Web Smk Swasta Brigjend Katamso Medan," J. Ilm. Saintikom, 2013

9] Kasiman, P. (2009). Aplikasi Web dengan PHP dan MySQL. Yogyakarta: ANDI.

10] Martin, J. (1990). Information Enginering Book II Planning and Analysis 2nd Edition. New Jersey: Prentice-Hall.

11] Peranginangin, K. (2006). Aplikasi WEB dengan PHP dan MySQL. Yogyakarta: ANDI. 